\title{
Designing Against the Status Quo
}

Vera Khovanskaya, Lynn Dombrowski, Ellie Harmon, Matthias Korn, Ann Light, Michael Stewart, Amy Voida

Innovation. Transformation. Disruption. These buzzwords suggest that the impacts of new technologies are all somehow revolutionary. Yet despite micro-disruptions to specific practices, new computing tools often fall short, reinforcing the status quo in new material forms. A smartphone appeals with the promise of working from the beach instead of the office; a worker breaks free from the office jail, only to be enrolled in expectations to be ever more available, on the clock even when supposedly on vacation at the beach. The oppression of the office has not been disrupted; instead, its reach has only expanded.

The re-entrenchment of the status quo often entails the simultaneous reinforcement of inequity. Uber and Lyft transform the taxi industry. The consumer experience is more blissful than ever: A GPS-based app puts a car at your beck and call; no need to walk to a commercial corridor to hail a cab; no miscommunicated street crossings. Liberated from exclusionary licensing systems, anyone can be an independent digital entrepreneur driving on their own schedule. Uber even offers a subprime leasing program for drivers without good credit; payments are auto-deducted from a driver's paycheck; lessees lose the freedom to work on competing platforms or pursue other jobs; drivers sleep in their vehicles, work 12-plus-hour shifts, and default on their payments.

Within the HCI community, there is growing interest in leveraging design as an agent of change in large-scale social challenges like sustainability, labor politics, and sexism. Yet the methodological repertoire we know is ill suited to the task. Practicing a traditional user-centered design process - one widely adopted in industry and taught in universities - would have us researching existing practices and needs in order to design technologies that might comfortably fit into existing routines. If we truly want to innovate, transform, and disrupt, we need new ways of working.

In this article, we report on a set of conversations that grew out of a workshop held at DIS 2016 [1]. We explore how we might innovate in both method and outcome to design interactive systems that are responsive to current and future societal challenges. In contrast to user-centered design, we look for ways to design against the status quo, working to thwart the routines, habits, and norms of a social life that is inequitable and unsustainable.

\section{A Transition for HCI}


Historically, interaction design has focused on identifying and attempting to close or narrow a "gap" between existing practice and technological capabilities. Dominant $\mathrm{HCI}$ approaches to design and research embrace socially conservative notions. Yet many social challenges - from sustainability to homelessness to food insecurity - are rooted in the ongoing reproduction of society as it already is. An apolitical design stance that uncritically reproduces the social status quo, while promoting new technologies as progressive because of their technical newness, is no longer acceptable.

Drawing together a variety of existing conversations on friction, queering, feminism, and adversarialism, new critical approaches to design share a dedication to breaking with tradition and challenging the status quo [1] . As Ann Light argues, "HCI can begin to tackle gender - and other - inequalities, not through attempting to co-opt design to particular ends, but by promoting design which is spaceful, oblique and occasionally mischievous" [2]. Rather than seeing design as a tool of immediate control, we are hopeful for design's affective potential in presenting alternative futures as less speculative than originally imagined.

\section{In Turning Away From the Status Quo, What are We Turning Toward?}

Across diverse disciplinary histories, design practices, and political stances, three guiding commitments form a foundation for working against the status quo.

Commitment to asking why. Designing against the status quo requires going beyond an observation of the current state of the world and designing "for it." In particular, it requires asking why the current state of the world has come to be. For example, in developing a framework for social-justice-oriented design work, Dombrowski et al. argue against a charity-based orientation. A focus on providing aid can ultimately misdirect resources, as it "ignore[s] the structural inequalities that produce the need for charity" in the first place [3]. This commitment also foregrounds the importance of how we frame our research and design problems; the questions we ask up front constrain the kinds of solutions and interventions we can later envision.

If we believe in the power of design to have an impact on issues at a global scale, then we must scale up our understandings of the problems in which we aim to intervene. This shift requires an active resistance to what we might think of as an "engineering" way of thinking - an assessment of the current state of the world, and modularized design of a "solution" that might make that current state of the world more manageable. Instead, we must ask why the state of the world is as it is and keep asking why until we begin to grasp the root causes of that problem. Designing against the status quo means setting our goals beyond the level of ameliorating symptoms, and moving more ambitiously toward design that challenges underlying problems. 
Commitment to history. Moving to frame our design inquiries in terms of underlying causes requires a renewed commitment to engaging with history. Understanding the whys of a particular situation requires understanding the histories that have sedimented into the present moment. Historical inquiry is an ally in seeking out strategic points of intervention, weaknesses in the structures of the status quo, and opportune sites for alternative supports, practices, and infrastructures.

Dislodging the sediment of the present is a significant challenge but also presents an opportunity for reconfiguring our tools. The past is multiply concretized in the present day, in forms of speech, habits of interaction, technical artifacts, and expectations of other people and technologies - a situation ripe for methodological innovation, where we might re-deploy familiar techniques like ethnography and design thinking in novel tandem arrangements with historical inquiry [4]. Engaging with history will go hand in hand with continued work to reach out to new disciplinary and methodological spaces - in particular, to zones of research and praxis in which scholars and activists have been formulating modes of resistance and tactics for challenging the status quo.

Commitment to new disciplinary engagements. HCI scholars have long reached out to allied disciplines as the field explores new ways of interacting with or against technology. Most recently, HCI scholars have begun drawing inspiration from a discipline with a history of praxis and resistance: feminist and queer theory. Queer theory's construct of troubling provides one set of strategies for working against the status quo. Designing explicitly "against the strengths of computing" can be a way of troubling a status quo that embraces the new and the technical as if they were always an improvement [2]].

Working against normativity may sometimes require relinquishing our own authoritative control through design. We might seek ways to intentionally, if less agentially, misdirect the status quo by telling new stories about technology or playing into already existing "swerves" of social life and technoscientific progress. There are many forms of normativity that make up the status quo, many opportunities for disruption, and many sources of inspiration: feminist and queer theory, postcolonial theory, media theory, artistic practice, punk rock, DIY culture, and more.

Inspired by Donna Haraway, we are reminded that there is no view from nowhere, no perfect god's eye view of the world from which to design regardless of whether we are in favor of or in opposition to the status quo. Our understandings of the world are rooted in our own personal histories and experiences along with the histories and experiences of those with whom we interact, work, design, teach, and learn. Designing against the status quo means recognizing, grappling with, and leveraging our own unique positionality - our disciplinary location, our positions of power, our personal biographies - and their respective possibilities and constraints. 


\section{Challenges and Tensions}

With these commitments in mind, we also face a set of challenges and tensions in bringing our diverse disciplinary histories, design practices, and political stances to bear on work to design against the status quo.

Immediate needs versus long-term goals. In designing against the status quo, we face the challenge of how to balance responding to both immediate and long-term moral imperatives - addressing the most pressing concerns while keeping sight of transformative goals that address underlying or systemic causes. For example, designing to address the problem of food insecurity might mean designing new ways to better distribute existing food resources in the short-term, but that work cannot be done at the expense of designing to trouble the inequities in transportation, jobs, or education that give rise to food insecurity in the first place [1]. These trade-offs must be acknowledged and engaged.

Within a university context, faculty are tasked with preparing students for the workforce in addition to providing a holistic education. Many of us thus feel a responsibility to usefully inculcate our HCI students with the necessary skills for contemporary user experience (UX) practice. That is, we often feel we have to teach students how to design for, rather than against, the status quo. While we are challenged in the immediate-term to teach practices and tools that we may judge to be less than ideal, our classrooms are also opportunities to highlight the limitations of UX practice and to help our students develop their own critical and reflective capacities.

The threat of recuperation. History teaches us that the same design practices that enable transformative change can also be subsumed into mainstream practice, absent their original political program. Our community has already wrestled with this threat of recuperation (the normalization of radical methods), when elements of participatory design were co-opted as a corporate activity without the pro-worker orientation that defined the original movement. Similarly, one might incorporate the motions of reflection or friction as a palliative gesture without taking up the ethos of working toward social justice in substantive ways.

Recognizing that recuperation will always be an imminent threat forces us to confront our own locations within institutions of technology production and design training. These present us again with both a challenge and an opportunity. The challenge is working tactically within the systems of the status quo to head off recuperation. The opportunity is to introduce ideas to audiences that might not otherwise be exposed to them. The flexibility of HCI offers opportunities for action, and as we move forward, we will have to continually reassess how best to leverage our proximity to an 
institutional locus of power in ways that might not only be co-opted but that also might give us - and others - the perspective to see new opportunities for change.

Designing for the world we want? A final tension foregrounded by work to design against the status quo concerns the question of whether we should design for an alternative future of a particular kind - or if we should aim, instead, to trouble the status quo in ways that explicitly refrain from articulating new, alternative sets of values and possibilities.

Tactics of troubling or friction can be appealing because they aim to intervene more indeterminately and as refusal to dictate what is right - creating space for alternative values to emerge and allowing for processes of becoming. Instead of working to replace the current status quo with another fixed alternative, we emphasize the livedness of design work, research, and computational artifacts to "make a space for flexible interactions of the future, rather than stipulate a desired outcome in societal terms" [2]].

Yet designing against the status quo is not about designing for just any change. Our motivations may often be rooted in desires for very specific change - to create more equitable futures, to redistribute resources, and to empower groups who have been disenfranchised from decision making in civic, social, and technological contexts. Allying with these groups requires taking explicit sides and embracing the messy, imperfect political work of building partnerships, facilitating others' questioning, and leveraging our skills to co-envision new futures and new designs.

\section{Conclusion}

Recognizing the importance of artifacts for shaping politics and possibilities, we hope to leverage design's close alignment with production and progress to find our way to the table and showcase the alternative worlds that could be possible. Even if we do not yet have perfect (or complete) methods for ensuring that design brings about more progressive and just futures, we cannot continue forging ahead with the world as it is. As we improvise and iterate on our practices, a series of questions help us to maintain an orientation that rebuffs and resists the world as it already is:

- Whose status quo? What should be destabilized?

- What's at stake? Now, what else?

- Who gives permission? Who disagrees? According to whom? Who else?

- What makes a good change? How does (can) change happen?

- What is my positionality, power, potential leverage?

- How can we overcome inertia, dislodge the sediment of history?

- What are the limits of design? 
Like method cards or inspiration toolkits, these questions and provocations can be called upon at many points within a design practice to remind us of the human stakes of our work and the alternative futures that may yet be possible. Our workshop concluded with a renewed commitment to exploring alternatives. We call on the broader HCI community to join us.

\section{References}

1. Harmon, E., Korn, M., Light, A., and Voida, A. Designing against the status quo. Proc. of the 2016 ACM Conference Companion Publication on Designing Interactive Systems. ACM, New York, 2016, 65-68.

DOI:https://doi.org/10.1145/2908805.2913020

2. Light, A. HCI as heterodoxy: Technologies of identity and the queering of interaction with computers. Interact. Comput. 23, 5 (Sept. 2011), 430-438.

DOI:http://dx.doi.org/10.1016/j.intcom.2011.02.002

3. Dombrowski, D., Harmon, E., and Fox, S. Social justice-oriented interaction design: Outlining key design strategies and commitments. Proc. of the 2016 ACM Conference on Designing Interactive Systems. ACM, New York, 2016, 656-671. DOI:https://doi.org/10.1145/2901790.2901861

4. Khovanskaya, V., Sengers, P., Mazmanian, M., and Darrah, C. Reworking the gaps between design and ethnography. Proc. of the 2017 CHI Conference on Human Factors in Computing Systems. ACM, New York, 2017, 5373-5385. DOI:https://doi.org/10.1145/3025453.3026051 